\title{
Congestion at Airports: The Economics of Airport Expansions
}

\author{
Jeffrey P. Cohen and Cletus C. Coughlin
}

C ongestion has been and continues to be a problem at many airports throughout the United States. For example, in the first five months of 2001, over 25 percent of the flights arriving at the nation's 11 busiest airports were more than 15 minutes late. ${ }^{1}$ Despite a decline in travelers and flights in 2001, which was associated with the recession that began that spring and the September 11 terrorist attacks, congestion remained a problem in some locations. ${ }^{2}$ For example, 16.2 percent of the flights bound for Lambert-St. Louis International Airport from May 1, 2001, through June 30, 2001, arrived late, with an average delay of roughly 55 minutes. Using the same period one year later, 16.3 percent of the arriving flights were delayed, with an average delay time of roughly 56 minutes. ${ }^{3}$

Congestion imposes costs on both the users and providers of airline transportation services. A common response is to expand the capacity of airports in the most afflicted regions. Consequently, airport expansions have occurred and are occurring in many major cities, including Atlanta and St. Louis. ${ }^{4}$ Figure 1 shows that the amount of federal, state, and local government spending on airports increased in all but two years between 1986 and $1999 .{ }^{5}$ Federal,

1 See Salant (2001)

2 The terrorist attacks also spurred increased screening of passengers and luggage, which generated other forms of congestion. See Coughlin, Cohen, and Khan (2002) for a discussion of aviation security and terrorism.

3 Data on average flight delays were found at < http://www.bts.gov/ ntda/oai/SummaryStatistics?DEMO/SummaryStatistics $>$

4 However, the current financial problems of airlines and airports have, at least temporarily, led to either the cancellation or delay of an estimated $\$ 16$ billion in capital projects at numerous airports, including ones in Los Angeles, Boston, and Phoenix. See Bayles (2001).

5 Bureau of Transportation Statistics web site: < http://www.bts.gov/ transtu/govfin/2001/tables/table_1b.html > .

Jeffrey P. Cohen is an assistant professor of economics at the Barney School of Business, University of Hartford, and Cletus C. Coughlin is deputy director of research at the Federal Reserve Bank of St. Louis. The authors thank Chuck Reitter for useful information pertaining to the Lambert Airport expansion. Heidi L. Beyer and Molly J. Dunn provided research assistance.

(c) 2003, The Federal Reserve Bank of St. Louis. state, and local funds for U.S. airports in 1999 totaled over \$20 billion, up from \$11 billion in 1985 (using constant, 1996 dollars).

Expansions are costly, complex, and controversial. For example, the cost of "Phase 1 " of the current expansion of Lambert-St. Louis International Airport is $\$ 1.1$ billion. The key component of this project is the construction of a new runway. ${ }^{6}$ To add this runway, the approved project entailed the acquisition of more than 1,500 acres of land, which ignited protests from affected homeowners and businesses; the reconfiguration of seven major roads; the movement of some airport support operations and the Missouri Air National Guard facility; and the construction of a new school. ${ }^{7}$

We begin our analysis by providing a discussion of how congestion arises and how it can be dealt with. Because the air transportation services provided by one airport are related to the services provided by many airports, delays at one airport have adverse effects on the movement of passengers and freight at other airports. 8 Thus, the expansion of one airport can assist the movement of passengers and freight at other airports. This interdependence provides an economic justification for a decisionmaking authority above the level of individual airports, such as a governmental body, to be involved in the approval as well as the financing of expansions. However, when both congestion and network externalities are present, the appropriate government actions may be to levy a tax, to provide a subsidy, or possibly to refrain from any intervention.

To justify a specific airport expansion, its benefits must exceed its costs. We examine how the benefits and costs of expansions are measured. We use the expansion of Lambert-St. Louis International Airport to illustrate many of the key points.

6 Lambert International Airport web site: < http://www.lambert-pmo.org/ about/phase 1/default.asp >

7 See Gilbert (2002) for details.

8 The relationships among airports create a network. One feature of this network is the "hub and spoke" system. Flights from various remote airports (the nodes on the spokes) converge on one airport (the hub). Flight schedules provide some time for passengers to change planes, before they depart for their final destinations. 


\section{Figure 1}

Percent Change in Federal, State, and Local Spending on Airports

Chained 1996 Dollars, 1986-99

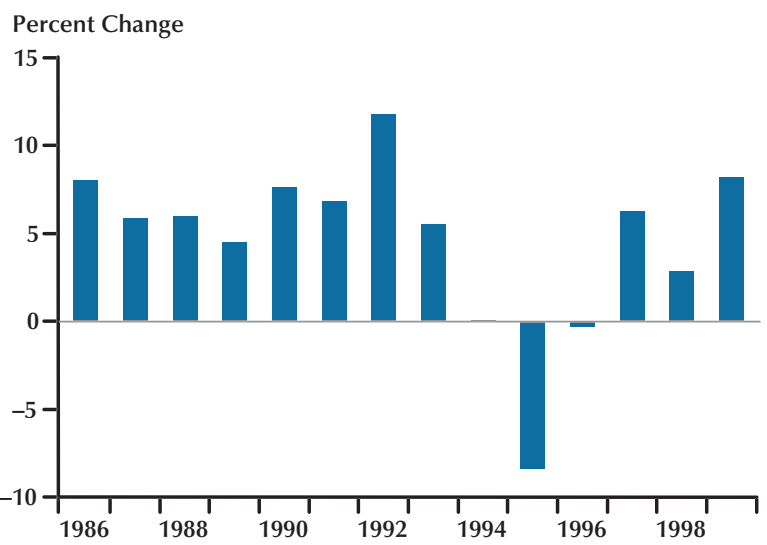

SOURCE: Bureau of Transportation Statistics web site.

We also examine two controversial aspects of expansions - the displacement of people and the environmental effects. The controversy as well as the cost of expansion projects has spurred the search for alternative ways to reduce congestion. One alternative that we examine, which reduces congestion by using existing capacity more efficiently, is congestion-based pricing of landing fees.

\section{ANALYZING CONGESTION IN THE AIR TRANSPORTATION NETWORK}

Expanding the capacity of an airport entails a multi-year capital expansion project to construct a runway and/or a terminal. The financing of expansions generally includes funding provided by a governmental body. An alternative in some cases to increasing an airport's infrastructure is to use its existing facilities more efficiently. This alternative approach to reduce the adverse effects of congestion can be implemented in the short run via the setting of appropriate prices or taxes.

The potential role of taxes/subsidies in responding to congestion as well as network externalities can be explained using marginal benefit/marginal cost curves. ${ }^{9}$ A potential traveler who wishes to fly

\footnotetext{
9 Initially, we assume airport capacity is fixed. Later, we relax this assumption. In the long run, airport authorities can choose both the size of an airport as well as the congestion tax that generates the optimal traffic volume. For additional details on congestion taxes and traffic volume for highways, see O'Sullivan (2003, Chap. 11).
}

\section{Figure 2}

\section{Optimal Congestion Tax}

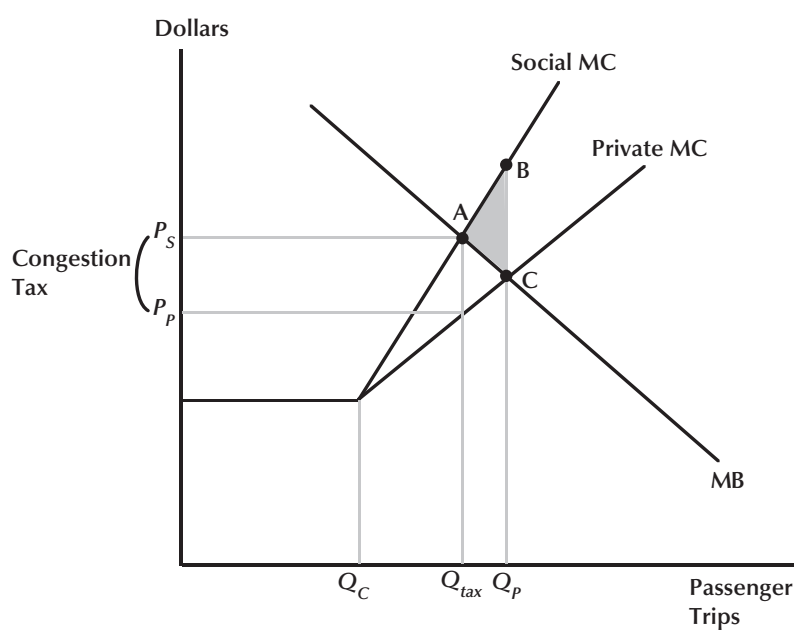

from St. Louis to Boston, for example, faces two costs - the airfare (" $x$ " dollars per trip) plus the opportunity cost of travel time ("y" dollars per hour). In Figure 2, with the units of measurement being dollars on the vertical axis and passenger trips on the horizontal axis, the marginal benefit (or demand) curve has a negative slope. This curve indicates, for our example, that when the price of air travel from St. Louis to Boston is high, only the few people who value their trips highly would choose to travel. As the price of a trip is reduced, more travelers will take this trip.

The explanation for the shapes of the private and social marginal cost curves is slightly more complicated. 10 The shapes hinge on the impact of congestion costs. At air traffic levels less than $Q_{C}$ in Figure 2, the marginal cost curve is flat. The flatness indicates that congestion has not set in yet, and the cost for passengers is the monetary cost of their tickets plus a "fixed" value related to the opportunity cost of travel. ${ }^{11}$ Consequently, the "social" marginal

\footnotetext{
10 Our exposition of the marginal cost curve is similar to O'Sullivan's (2003) analysis for highways. Neither exposition attempts to directly link the marginal cost curve with a supply curve; however, the monetary cost of airfare is related to a supply curve. Instead, we rely upon the principle that the socially optimal number of passenger trips occurs at a quantity where the marginal benefits curve intersects the social marginal cost curve.

11 With no time delays stemming from congestion, travel time is fixed. Thus, the total value of travel time is also fixed.
} 
cost curve coincides with the "private" marginal cost curve.

For air traffic levels greater than $Q_{C}$, however, the marginal cost curve is upward sloping. The positively sloped part of the private marginal cost curve can be understood by considering the notion that, beyond some threshold level, when a particular individual chooses to consume additional air travel, he adds additional traffic to the system, which slows down his own travel. Additional passenger trips translate into more flights, which is one source of congestion. In addition, more passengers cause more crowded airport terminals, creating delays at ticket counters and security checkpoints. When passengers anticipate these delays, they arrive at the airport earlier and increase their travel time. Moreover, additional passenger trips result in increased delays at the baggage claim carousel at the end of a trip. Thus, we are assuming that trip time varies directly with the number of passenger trips. This longer trip time increases the marginal passenger's own trip cost, due to the higher opportunity cost of the travel time, which is added to the monetary cost.

When accounting for congestion in the manner described above, the social marginal cost curve differs from the private marginal cost curve. Namely, when an additional passenger uses the airport more, in addition to increasing his own travel time by adding to congestion, this passenger increases the travel time of other airport users as well. This passenger does not take this additional cost into account, so existing travelers could be made better off if the would-be passenger did not travel. This additional cost causes the social marginal cost curve to lie above the private marginal cost curve.

This increase in total travel time can be calculated by multiplying the total number of airport users by the additional travel delay that the marginal user generates. At levels of passenger trips slightly greater than the congestion threshold, $Q_{C}$, this travel congestion externality is small, so the difference between the social and private marginal cost curves is relatively small. But as the number of passenger trips rises, an individual increasing his air travel adds greater cost to other travelers, due to the assumption that trip time is an increasing function of passenger volume. As a result, the difference between the social and private marginal cost curves is larger at higher levels of passenger traffic.

The socially optimal level of air traffic in this context occurs at $Q_{\text {tax }}$ in Figure 2, where the marginal benefit curve intersects the social marginal cost curve. Note that this level of passenger trips is less than $Q_{P}$, which is the level of passenger trips associated with the intersection of the marginal benefit and private marginal cost curves.

One way to achieve the socially optimal level of passenger trips, which requires the marginal benefits of air travel to equal the social marginal costs, is through a congestion tax on air travel from St. Louis to Boston. In Figure 2, a tax per unit of air traffic volume equal to the distance from $P_{P}$ to $P_{S}$ will yield this socially optimal level of passenger trips. The cost associated with the tax forces each traveler to pay for the costs that his travel imposes on others. The net gain resulting from the tax is represented by the triangle $A B C$. The net gain reflects the fact that for a level of passenger trips $Q_{P}$, marginal social costs exceeds marginal benefits by the distance from $B$ to $C$. The tax causes passenger trips to decrease from $Q_{P}$ to $Q_{\text {tax }}$ and eliminates the gap between marginal social costs and marginal benefits. Thus, the net gain is the sum of the differences between marginal social costs and marginal benefits as passenger trips decrease from $Q_{P}$ to $Q_{\text {tax }}$.

A congestion tax, however, is not the only policy option. An alternative policy, shown in Figure 3, is to expand the airport at which the congestion is present. Airport expansion shifts the private and social marginal cost curves rightward. In addition, the congestion "threshold" occurs at a larger number of passenger trips, increasing from $Q_{T}$ to $Q_{T X}$. Whether congestion persists depends not only on the size of the expansion, but also on the elasticity of air travel demand. ${ }^{12}$ If travel demand is relatively inelastic, then it is likely that the expansion leads to a new equilibrium level of passenger trips, $Q_{I}$, below the congestion threshold. In this hypothetical example, the relatively inelastic demand implies that consumers of air travel are not very responsive to the lower cost of travel, so quantity demanded does not increase by enough to create additional congestion. If demand is relatively elastic, however, then it is possible that the new equilibrium, $Q_{E}$, will occur above the congestion threshold, and the social marginal cost will be greater than the private marginal cost. Because consumers are relatively responsive to changes in the trip cost, the expansion

\footnotetext{
12 If a given percentage change in trip cost, say a 1 percent decline leads to a relatively small change in air traffic volume, say a less than 1 percent increase, then the price elasticity of air traffic demand is inelastic. If, however, the 1 percent decline in trip cost is associated with a more than 1 percent increase in air traffic volume, the price elasticity of air traffic demand is elastic.
} 


\section{Figure 3}

\section{Social and Private Marginal Cost Before and After an Airport Expansion}

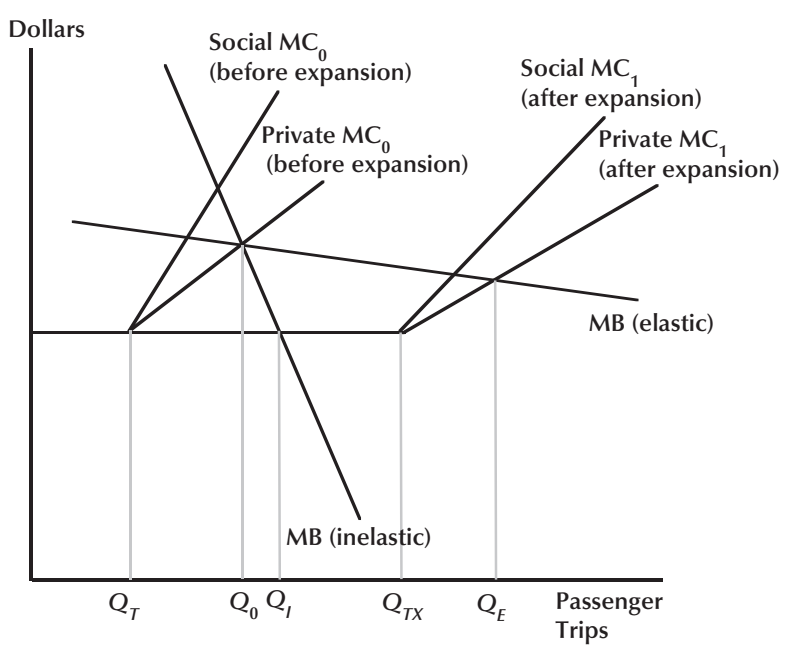

leads to a relatively large increase in the quantity of passenger trips demanded; thus, congestion persists. ${ }^{13}$

The preceding discussion ignores the crucial issue of whether a specific expansion generates benefits greater than its costs. In the example, depending on the elasticity of air traffic demand, travelers benefit by avoiding some or all congestion costs. The reduced congestion costs also induce more travel, which provides additional benefits. Reduced congestion also provides benefits for the providers of air transportation services. For example, airlines are likely to benefit in the form of reduced operating costs. Later, we examine how to calculate and compare the value of the benefits with the costs of an expansion.

The preceding discussion also focuses on congestion at a single airport and, as a result, ignores a key feature of the air transportation system. Accounting for the network structure of the hub and spoke system, while temporarily ignoring congestion issues, leads to a somewhat different picture concerning airport expansions. If the local airport planning authority makes a decision on the desired level of passenger capacity by equating the local (or private) marginal benefits to the marginal costs,

\footnotetext{
13 According to O'Sullivan (2003), a similar phenomenon of "latent demand" occurs for highway expansions, contributing to the continuation of congestion following the expansion.
}

\section{Figure 4}

\section{Airport Expansion to Account for Network Externalities}

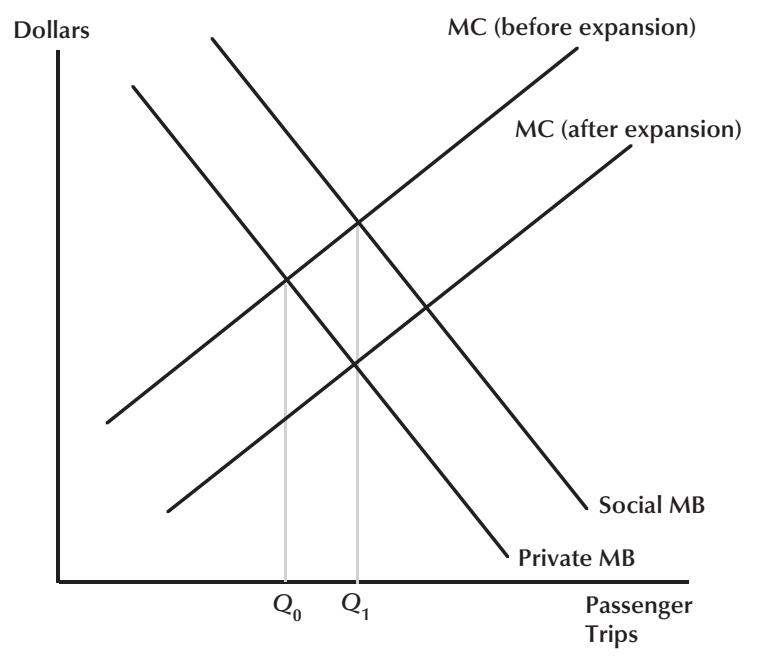

then it is possible that there would be a suboptimal level of capacity. Namely, the hub and spoke network structure of the air transportation system implies that individuals who use a particular hub airport as a stopover point receive benefits in the form of reduced travel time from use of the hub airport in one leg of their travel.

In the specific case of St. Louis, if Lambert Airport does not expand, then it will cause congestion and slowdowns throughout the country, even on some flights that do not go through St. Louis. Thus, if a local authority chooses the level of airport capacity by considering only the local benefits, then equating the local marginal benefits to the marginal costs would lead to $Q_{O}$ passenger trips (in Figure 4) and a passenger trip capacity that is too small. The reason for such a conclusion is that the social marginal benefits of air traffic capacity are likely to be greater than the local marginal benefits.

The socially optimal level of air capacity provision, however, occurs where the social marginal benefit curve intersects the marginal cost curve (before expansion). In Figure 4 this intersection yields a passenger trip volume of $Q_{1}$. One possibility for attaining point $Q_{1}$ is further expansion of local airports. This expansion, which lowers the marginal cost of passenger trips by shifting the marginal cost curve to the right, can be accomplished through subsidies (or intergovernmental grants) to the local 
airport authorities from the federal government. ${ }^{14}$ The resulting equilibrium of passenger trips occurs at the socially optimal $Q_{1}$, where the new marginal cost curve intersects the local (private) marginal benefit curve.

If we consider both types of spillovers simultaneously - the congestion externality and network externality - we obtain an ambiguous policy recommendation. Namely, in Figure 5, the social marginal cost curve lies above the private marginal cost curve because of the congestion externality, and the social marginal benefit curve lies above the private marginal benefit curve because of the network externality. The socially optimal level of airport traffic, $Q^{*}$, occurs at the intersection of the social marginal benefit curve and the social marginal cost curve. In general, this occurrence may be at a passenger trip level that is greater than, less than, or equal to the level that would be attained privately.

In Figure 5, the social marginal benefit and social marginal cost curves are drawn so that government intervention would not be necessary. In this case, the congestion effect, which can be mitigated by a tax, is exactly offset by the network effect, which can be accommodated by a subsidy. If the congestion effect were relatively more pronounced than the network effect, then governmental intervention by means of a tax would be justified in theory. On the other hand, if the network effect were relatively more pronounced than the congestion effect, then governmental intervention by means of a subsidy would be justified in theory. Thus, when accounting for both types of externalities, the policy prescription is ambiguous unless one knows the sizes of the effects. To accurately determine the amount of the tax or subsidy to address both externalities simultaneously, one must know the sizes of both the network and congestion effects.

\section{MEASURING THE BENEFITS AND COSTS OF AIRPORTS AND AIRPORT EXPANSIONS}

Nearly all studies attempting to measure the benefits and costs of airports and airport expansions are encompassed by the following categories of analysis:

\footnotetext{
${ }^{14}$ The suggestion that subsidies can lead to the social optimum ignores the practical problem of financing the subsidy, which may entail the use of distortionary taxes.
}

\section{Figure 5}

\section{Congestion and Network Externalities}

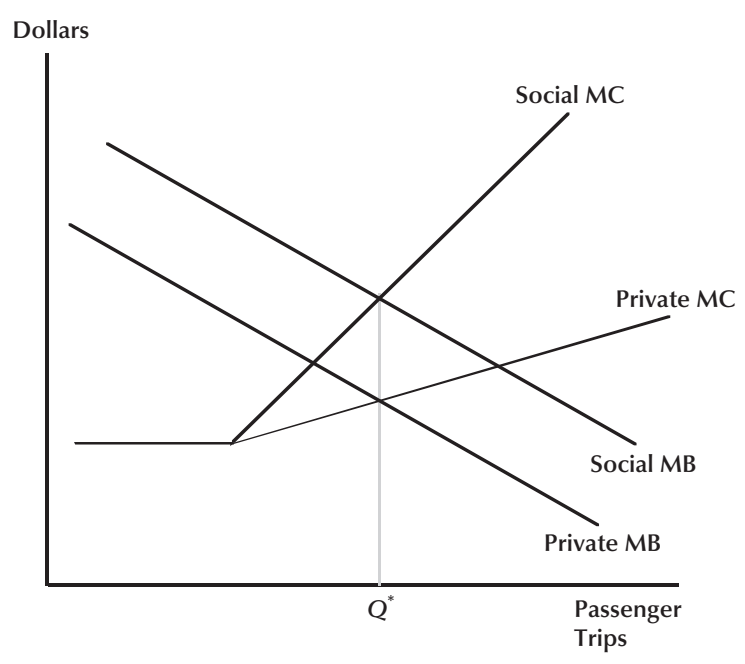

- input-output models,

- production function/growth studies, or

- benefit-cost analyses. ${ }^{15}$

For the analysis of individual expansion projects, a benefit-cost analysis is a crucial component for determining whether an expansion is justified. We will examine this approach after highlighting some results from the two other approaches that are used to analyze the economic impact of airports.

\section{Input-Output Models and Local Economic Impacts of Airports and Airport Expansions}

A standard tool for calculating the economic impact of airports in general, as well as the economic impact of a specific airport, is an input-output model. ${ }^{16}$ The impact of an expansion can be estimated as well. What this tool cannot provide, how-

${ }^{15}$ Pfähler (2001) notes that computational general equilibrium analysis is the state-of-the-art method to estimate the microeconomic effects of large publicly funded projects. This approach, because of its complexity and cost, is not common in airport studies. Thus, we do not examine this approach

${ }^{16}$ An input-output model is a mathematical description of how all the sectors of an economy are related. For an introduction to input-output models and their limitations, see Coughlin and Mandelbaum (1991), Pfähler (2001), and O'Sullivan (2003). For advanced discussions, see Miller (1998) and Lahr and Dietzenbacher (2001). 
ever, is a rigorous determination of whether a specific project should be undertaken. ${ }^{17}$

A study of the economic impact of LambertSt. Louis International Airport by the Mumphrey Group (1996) estimated that for 1994 the economic impact of Lambert Airport was $\$ 5.1$ billion, supporting 53,900 jobs, which is 4.4 percent of the total jobs in the St. Louis area. Based on forecasts of future aircraft operations, passenger enplanements, and cargo, for 2015 the economic impact of Lambert was estimated to be $\$ 7.8$ billion, with employment of 84,500 . This estimate of the future economic impact did not depend on the proposed expansion program; however, separate from the ongoing operations of Lambert, estimates of the impact of total construction spending at Lambert (including the runway expansion) were generated. Over a ten-year period, the total estimated impact of new construction at Lambert was $\$ 4.7$ billion, or $\$ 470$ million per year. This impact translates into annual household payroll of $\$ 108$ million and 4,300 jobs.

Frequently, airport expansions have occurred simultaneously with the growth of an area. According to former Atlanta mayor Bill Campbell, as reported by McRainey (2002), Atlanta's Hartsfield Airport "anchors a regional economy that in 1998 outpaced the U.S. economic growth by more than two to one. And, the benefits of this output, including the performance of our airport, extend well beyond the boundaries of our region." The 1980 terminal addition and the 1994 new international concourse have "helped Atlanta become a business magnet." What is difficult to measure, however, is the extent to which the airport expansions contributed to economic growth.

Cooper (1990) notes that the purpose of economic impact studies is "more political than analytical." 18 Thus, one might have more confidence in studies of the economic impact of airport expansions in which the authors are less likely to have a political or economic stake in the results. One academic study of Amsterdam Schiphol Airport's expansions by Hakfoort, Poot, and Rietveld (2001) finds relatively modest economic impacts. Namely, they find that

\footnotetext{
${ }^{17}$ See Niemeier (2001) for a discussion of the (mis)use of input-output analysis by the airline industry and for a statement that such an approach cannot answer whether the benefits of an expansion exceed its costs.

${ }^{18}$ A similar conclusion was reached by Sanders (2002) in a review of convention center expansion studies. In a similar vein, Pfähler (2001) notes that input-output studies are more useful for generating political support for an expansion project than in assessing its merits.
}

if the Schiphol airport had stopped growing in 1987 , there would have been 42,000 fewer jobs in the Greater Amsterdam region in 1998. ${ }^{19}$

In summarizing their usefulness, Pfähler (2001) notes that input-output studies capture only some of the economic effects of a public expenditure program and that these effects may not be the relevant ones. Such studies are focused on the short-run demand effects and ignore the economic reasons for these projects. These projects should deliver services either to be used as intermediate inputs to produce goods/services by private firms or as a final consumption good/service. In the former case, the projects should stimulate productivity and growth; in the latter case, the projects should expand the consumption opportunities of consumers. Thus, an input-output approach will necessarily fail to provide an adequate analysis of a specific expansion project.

\section{Production Function/Growth Studies}

A common assertion is that an airport expansion will stimulate growth. This assertion is part of a view that public capital is a key ingredient for economic growth in a region. A large literature, propelled by Aschauer (1989), has addressed this issue. Aschauer (2000a) summarized this literature by noting that the estimates concerning the effect of public capital investment on private output ranged from very high to very low (low being not only zero, but negative).

In the present context, the issue is the impact of airport infrastructure on growth. Generally speaking, transportation infrastructure has been found to matter for growth. For example, Easterly and Rebelo (1993) find that infrastructure capital, especially that associated with transportation and communications, is related positively to economic growth. ${ }^{20}$ However, few studies have focused on airport infrastructure. One exception is Cohen and Paul (2001), who estimate that a doubling of airport infrastructure capital in a particular state would lead to a 10 percent fall in manufacturing costs in

\footnotetext{
${ }^{19}$ Montalvo (1998) reported results of a 1991 study by the Air Transport Action Group that found the worldwide average of between 2,500 and 7,500 total jobs generated per million passengers. The total economic impact per million passengers is between $\$ 120$ million and $\$ 1.5$ billion. See Pfähler (2001) for a number of impact studies.

20 Other studies have found that a given percentage increase in core capital (i.e., streets, highways, mass transit, sewers, and water systems) tends to have larger effects on output than other types of public capital. See Aschauer (1989, 2000b), Munnell (1990), and Lighart (2000).
} 
that state. Thus, significant cost savings may accrue to the manufacturing sector from airport investments. ${ }^{21}$ A second exception is Brueckner (2003), who examines the impact of changes in passenger enplanements in metropolitan areas on employment in the given area. He finds that employment in a metropolitan area increases by 1 percent for every 10 percent increase in passenger enplanements. To reiterate, however, the issue of whether a specific expansion is justified is not answered by such studies.

\section{Benefit-Cost Analysis}

Plans to expand the capacity of airports are subjected to a required benefit-cost analysis (BCA) prior to approval by the Federal Aviation Administration (FAA) (1999). During a BCA, the benefits realized and the costs borne by the producer and the consumers of the output, as well as the benefits realized and the costs borne by anyone else (so-called third parties), are incorporated in the analysis. A BCA, especially for a large project, can be very complicated. We examine key aspects of the BCA process using information from a BCA of Lambert-St. Louis International Airport.

Background on the Lambert-St. Louis International Airport Expansion. During 2001, passenger traffic at Lambert totaled 26.7 million, making Lambert the 17th busiest airport in the United States. ${ }^{22}$ Passenger traffic during 2001 declined sharply, falling nearly 13 percent from the level of 30.6 million in 2000. Similar to airports throughout the United States, the sharp decline in passengers can be tied directly to the national economic recession that began during the spring of 2001 and the terrorist attacks of 9/11. The airport serves the 2.6 million residents and the businesses in the St. Louis metropolitan statistical area. In addition, especially because it is a hub for American Airlines, the airport plays a key role in the nation's air transportation system. ${ }^{23}$ The airport has two parallel air carrier runways that are separated by 1300 feet. When adverse weather conditions occur,

\footnotetext{
${ }^{21}$ Two other related issues-how public capital is financed and how it is used-have drawn attention. Barro (1990) showed that the benefits from productive government spending should be compared with the costs of the distortionary taxes required to fund the spending. See Aschauer (2000b) for a simultaneous estimate of these two effects. See the boxed insert for a discussion of the financing of airport expansions.

22 Airports Council International web site: < http://www.airports.org/ traffic $>$.

${ }^{23}$ During the BCA, Lambert was the hub for TWA. Subsequently, American Airlines acquired TWA and uses Lambert as one of its hubs.
}

the airport is reduced to one precision instrument approach, which causes the capacity of the airport to decline 40 percent and congestion costs to increase substantially.

Step 1: Identify Project Objectives. Possible objectives for an airport expansion project include the following:

- Reduce delays associated with airport congestion,

- improve the efficiency of airport operations,

- increase the number of aircraft and passengers the airport can serve, and

- permit new service by accommodating larger and more efficient aircraft at the airport.

The Lambert infrastructure project was motivated by an assessment that the existing airport was already severely constrained (especially during bad weather) and that projected demand could not be met without unacceptable operational delays. A related assessment was that Lambert, especially because of its role as a hub, should not be allowed to become a bottleneck that would have detrimental effects throughout the national system. ${ }^{24}$ Thus, the proposed project would allow the airport to effectively and safely accommodate projected levels of aviation activity at an acceptable level of delay by increasing airfield capacity for all types of weather conditions and decreasing delays at Lambert as well as nationwide.

Step 2: Specify Assumptions About Future Airport Conditions. Generally, to formulate reasonable plans, policymakers and researchers make assumptions about the projected growth in demand for airport services, changes in airport facilities and capacity that are likely to occur independently of the proposed project, and likely technological advancements in air traffic control. Forecasts of projected growth in airport activity are both difficult to make and very important. Incorrect forecasts will likely lead to a poor timing of airport investments, with overly optimistic (i.e., too high) forecasts causing underused facilities and with overly pessimistic (i.e., too low) forecasts imposing costs in terms of delays and inconvenience. ${ }^{25}$ Similarly, ignoring

\footnotetext{
${ }^{24}$ It was also recognized that Lambert provides economic benefits throughout the region and that those benefits would be threatened by an inadequate airport.

${ }^{25}$ Estimates of passenger enplanements and aircraft operations for 1997 through 2010 for the Lambert expansion were generated by the FAA. For 2011 through 2021, national estimates of the growth of passenger enplanements and aircraft operations were assumed to hold for Lambert. See FAA (1997).
} 


\section{FINANCING OF EXPANSIONS}

A financial plan is a key component of any airport expansion project. ${ }^{1}$ Three major sources are used for financing the expansions of U.S. airports. One of these is grants from the federal government through the FAA's Airport Improvement Program (AIP), which is discussed in more detail below. AIP grants are funded with ticket taxes and fees that are deposited into an airport's trust fund. The second source of funds, passenger facility charges (PFCs), are additional fees charged by airlines designated for capital improvements. Approximately $\$ 1.5$ billion in PFCs are collected each year. ${ }^{2}$ The third major source for airport financing, also discussed by Truitt and Esler (1996), consists of tax-exempt bonds issued by airports, which are based upon the expected future revenue streams of the airports. ${ }^{3}$ Nearly 80 percent of all funding from these airport revenue bonds are allocated to the top 71 airports, while the more than 3,000 remaining airports share what is left. Funds generated by the new facility are used to repay the principal and interest on these bonds.

\section{Economic Issues Associated with AIP Grants}

An important issue with respect to AIP grants is their effect on the recipient's spending. One hypothesis is that, when a state or local government receives grant funds from a higher level of government, the lower level of government acts in the interests of the average constituent-the median voter. The lower level of government treats the grant funds as if they were an increase in the median voter's disposable income, a certain por-

1 The financial condition of airlines and airports has deteriorated in recent years. See Golaszewski (2003) and Gillen and Lall (2003) for analyses of the financial shockwaves stemming from the events of 9/11. One possibility is that financial plans and the benefit-cost analyses supporting major capital improvements developed prior to 9/11 may no longer be justified.

2 Information on PFCs and revenue bonds was obtained from the Air Transport Association's Airline Handbook (2001, Chap. 7).

3 The Air Transport Association's Airline Handbook refers to these as general airport revenue bonds, which amounted to $\$ 53.6$ billion since 1982 and have comprised over 95 percent of all airport debt. The bonds are serviced by airline revenues (e.g., landing fees and terminal building rentals), nonairline revenues (e.g., parking lot revenues, rental car concessions, terminal concessions, and general aviation fees), and interest income from various funds and accounts.

\section{Figure B1}

\section{Per Capita AIP Grants to Selected States 1988-96}

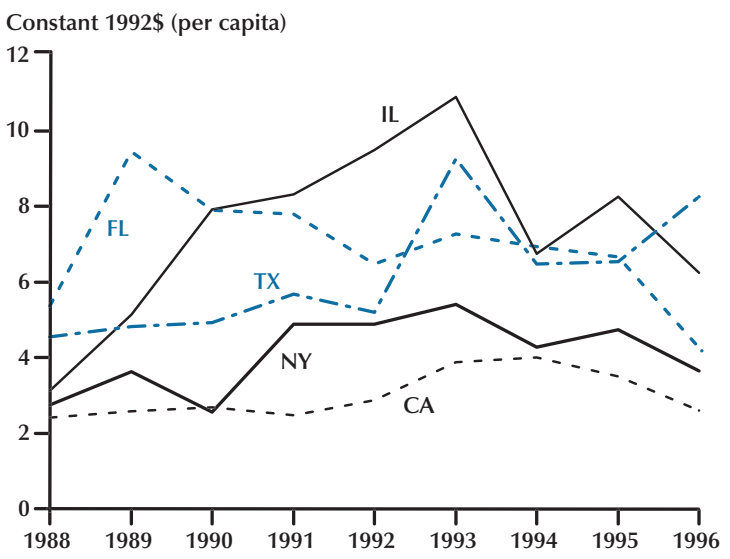

SOURCE: Cohen (2002).

tion of which would be spent on the designated public services - in this case, airport usage. (That portion depends on the voter's marginal propensity to consume on that category of public services.) So, if the lower level of government acts in the interest of the median voter, one would expect it to spend a share of the grant equal to the median voter's marginal propensity to consume that public good or service out of his disposable income.

The empirical evidence for most types of public services does not support this theory. Namely, many researchers, such as Case, Rosen, and Hines (1993), have found that the impact of intergovernmental grants on state and local public expenditures exceeds the marginal propensity to consume out of disposable income. This has been called the "flypaper effect" because grant money tends to stick where it hits. ${ }^{4}$ Cohen (2002) finds significant evidence of a flypaper effect for AIP grants. That is, he finds that the effect of AIP grants on state and local airport spending is greater than the median voter's marginal propensity to spend on airports, implying the presence of a flypaper effect for airports.

The figure shows that AIP grants per capita have varied over time in many states that have (Continued on p. 17)

\footnotetext{
4 See Gramlich (1977)
} 


\section{(Continued from $p .16)$}

large hub airports (i.e., an airport with greater than 1 percent of the nation's passenger enplanements). The U.S. Congress has debated reauthorization of the AIP on more than one occasion in recent years, which leads one to question how states and localities respond to cuts compared with increases in AIP grants. Specifically, when federal government grants are reduced, do states and localities reduce their own spending in the same way they increase their spending when grants are increased? States and localities may also try to pick up the slack when grants from the federal government are cut. Cohen (2002) looks at the question of symmetric state and local airport expenditure responses to cuts and increases in AIP grants over the period 1988-96, and he cannot reject the hypothesis that the state and local spending response is symmetric in the cases of cuts and increases. This is important because it implies that states and localities do not replace funds for airport expenditures with funds from other areas.

One other possible application of intergovernmental grants discussed in the public finance literature in Oates (1972) is to induce states to internalize spillovers. In other words, a higher level of government (such as the FAA) may use grants to subsidize states and localities for the benefits that they confer upon other states through their airport spending choices, as proposed by Cohen (1997). This subsidy would result in a shift in the marginal benefit curve that would further result in a higher equilibrium level of airport spending. ${ }^{5}$ Thus, if these grants were used to subsidize all states that confer benefits upon other states, the subsidies could effectively induce all states to spend the socially optimal amount on airports. Ideally, however, this type of subsidy would be done at the individual airport level. The practical implementation of such a policy would be very challenging because the complexity of the air transportation network would make it extremely difficult to assess the magnitude of the spillover benefits.

5 Coughlin, Cohen, and Khan (2002) present a similar marginal benefit/marginal cost framework in more detail for the optimal provision of aviation security. future changes in airport facilities and capacity can lead to ill-timed investments. For example, a project to reduce runway congestion may be unwise if some other project affects the benefits of the proposed project. Finally, a runway expansion project may be unwise if scheduled improvements in air traffic equipment will accomplish the same result.

Step 3: Identify the Base Case. To assess one course of action, it is necessary to compare it with an alternative. One alternative, the base case, is not a "do nothing" alternative, but rather a reasonable course of action, absent the proposal being scrutinized. The base case assumes that airport managers will make optimal use of the existing and planned (i.e., currently underway and/or funded) airport infrastructure. In addition, as problems arise due to increases in airport traffic, airport managers, users, and air traffic managers are assumed to respond as best they can. Without question, the assumptions underlying this alternative can affect the decision of whether or not to undertake an expansion project. ${ }^{26}$ With respect to the Lambert expansion, the assessment of the no-action alternative was that it

\footnotetext{
${ }^{26}$ For details, see Appendix J of the FAA's Record of Decision that was signed on September 30, 1998
}

would neither solve the capacity shortcomings nor mitigate the delays.

Step 4: Specify Alternatives To Meet the Objectives. With respect to Lambert, numerous alternatives were examined and eliminated from detailed analysis. These alternatives included the increased use of other modes of transportation, such as railroads, buses, and automobiles; the construction of a new airport to replace Lambert; a multiple airport system including Lambert and a supplemental airport; numerous airfield alignments; and other on-airport alternatives, such as the use of advanced navigational aids.

Various reasons led to the rejection of many alternatives. The increased use of other modes of transportation was rejected because it did not meet either local or national aviation needs and it would not have enhanced Lambert's contribution to the region. The construction of a new airport was rejected because of time and cost requirements. Moreover, other airports in the region could not fulfill the need for a new runway for various reasons, including Lambert's role as a hub, the lack of facilities at other airports, and airspace constraints. The airfield alignment alternatives were rejected because they were infeasible or because of environmental 
reasons. Several on-airport alternatives were eliminated because they did not provide sufficient capacity or they did not allow for operations considered critical for a hub airport.

Based on discussions between airport officials and the FAA, an agreement was reached in February 1997 that the only feasible alternative to the airport's system of operation at that time was the airport sponsor's preferred plan for expansion. Thus, the comparison in the BCA was between the baseline and the alternative known as $\mathrm{W}-1 \mathrm{~W}$. The baseline alternative was to maintain Lambert in its present configuration with no additional capacity, whereas alternative $\mathrm{W}-1 \mathrm{~W}$ was the construction of a new runway and the extension of an existing runway. The planned completion date was late 2001, with 2002 being the first full year of operation.

Step 5: Determine the Evaluation Period. The evaluation period is the number of years over which the benefits and costs of an investment are considered. To determine an appropriate evaluation period, one must first determine the economic life of the investment, which is the length of time the asset is expected to achieve its goals in a costeffective manner. Generally speaking, the FAA uses an economic life of 20 years beyond the completion of construction for major airport infrastructure projects. For the Lambert expansion, the evaluation period began with the expected start of construction in 1998. Benefits were first expected from W- $1 \mathrm{~W}$ in 2002 and were expected to continue for 20 years through 2021.

Step 6: Measure and Compare the Benefits and Costs of Alternatives. The benefits of capacityrelated airport projects primarily stem from the cost savings to airport users. A new runway, for example, should reduce aircraft, passenger, and cargo delay during normal airport operations. The costs of delay are incurred primarily by aircraft operators via more aircraft operating hours, passengers via longer trip times, and cargo shippers via longer shipping times. ${ }^{27}$ Estimates of the time savings associated with an expansion project are generated with capacity simulation models.

The time savings must be translated into a single overall monetary measure. All values for benefits as well as costs, regardless of the year in which the

\footnotetext{
27 One complication arises from the fact that an airport expansion project, because it improves service, will cause greater use of the facility than would have occurred without the investment. These additional users will place new demands on the facility, eroding to some extent the per operation delay savings to preexisting airport users.
}

benefits or costs arise, are expressed in constant (real) dollars. The FAA provides instructions as to the appropriate source for converting the following: (i) the reduction in aircraft delays into operating cost savings, (ii) the reduction in passenger travel delays into passenger travel time values, and (iii) the reduction of air cargo delay hours into opportunity cost savings.

Obviously, the benefits of any alternative will be at least partially offset by its costs. Costs include all capital, labor, and natural resources required for each alternative, no matter who-a governmental unit, the flying public, the general public, or some other group - bears the cost. Most airport projects involve relatively large expenditures at the beginning of a project in return for a flow of future benefits. Because a dollar expended today is more costly than a dollar expended later and a dollar of benefits received today is more valuable than a dollar of benefits received later, future cash flows must be converted into present value to allow for a meaningful comparison of a project's benefits with its costs.

The formula for the present value (PV) of a future benefit or cost to be received/incurred $n$ years from the present is

$$
P V=V_{n} /(1+r)^{n}
$$

where $V$ is future value in year $n$ in constant dollars, $r$ is the annual real discount rate, and $n$ is the number of years from the base year.

The PV formula allows a comparison of the benefits and costs for each alternative to see which, if any, is the most attractive. Various comparison methods are used, suggesting that no one method is superior to the others. Here, we will restrict our attention to two methods that are recommended when federal grants are involved - net present value (NPV) and benefit-cost ratio (B/C).

The formula for the calculation of NPV is

$$
N P V=\sum_{t=0}^{k}(B-C)_{t} /(1+r)^{t},
$$

where $B$ is future annual benefits in constant dollars, $C$ is future annual costs in constant dollars, $r$ is the annual real discount rate, $k$ is the number of years from the base year over which the project is to be evaluated, and $t$ is an index from 0 to $k$ representing the number of years from the base year.

To be selected, an alternative must meet two conditions. First, it must have a positive NPV - that is, its benefits must exceed its costs. Second, the 
selected alternative must have an NPV exceeding all other alternatives. ${ }^{28}$

One problem with ranking projects using NPV involves comparisons of mutually exclusive alternatives of greatly different sizes. For example, assume two mutually exclusive alternatives - one with a \$1 billion cost and a $\$ 100$ million NPV and the other with a \$100 million cost and a \$30 million NPV. Based on the NPV, the former alternative would be chosen over the latter. If the airport is able to borrow as much as required to undertake all worthwhile projects, the NPV criterion would yield the correct choice.

However, if the airport is constrained in the amount of debt it can issue, say to $\$ 1$ billion, and has several other independent potential projects with positive NPVs, then it may be best to select the $\$ 100$ million alternative and use the remaining $\$ 900$ million to fund the other projects. In this way, the $\$ 1$ billion of borrowed funds might yield a sum of NPVs in excess of $\$ 100$ million.

A second method of comparing benefits with costs is the $\mathrm{B} / \mathrm{C}$, which is simply the PV of benefits divided by the PV of costs. The formula for this calculation is

$$
B / C=\left\{\sum_{t=0}^{k} B_{t} /(1+r)^{t}\right\} /\left\{\sum_{t=0}^{k} C_{t} /(1+r)^{t}\right\} .
$$

Obviously, projects with positive NPVs will have $\mathrm{B} / \mathrm{Cs}$ greater than 1 . However, the $\mathrm{B} / \mathrm{C}$ method might fail to answer correctly the question of how to accomplish a project's objectives most effectively. Analogous to our preceding discussion, problems with using this method can arise when comparing mutually exclusive projects of different sizes. Note that the larger alternative in the preceding example has a $B / C$ ratio of 1.1 , while the smaller alternative has a $\mathrm{B} / \mathrm{C}$ ratio of 1.3 . Recall that, depending on funding options and other considerations, the smaller project may or may not be the better alternative.

With respect to the BCA for the Lambert expansion, a number of economic and programmatic assumptions were made. Benefits and costs were denominated in 1997 dollars and, following FAA guidelines, discounted at 7 percent. Benefits consist of cost savings to passengers and to airlines. Passengers avoid delays. As a result, cost savings to passengers are the value of the time saved. The value of

\footnotetext{
${ }^{28}$ Note that this criterion is consistent with the notion discussed earlier that decisionmakers should choose the level of airport capacity such that the marginal benefits of an expansion equal the marginal costs. Such an action would maximize the net benefits of an expansion.
}

passenger time was assumed to be $\$ 27.90$ per hour. Similarly, airlines avoid delays, so the cost savings are in the form of reduced variable operating costs. Variable operating costs per hour were assumed to be $\$ 1,189$ in $2002, \$ 1,333$ in 2010 , and $\$ 1,581$ in 2021.

Alternative $\mathrm{W}-1 \mathrm{~W}$ was assumed to be completed in 2001, with benefits beginning in 2002 and extending through 2021. Table 1 shows the calculated benefits in (discounted) present value dollars. With passenger delay savings of $\$ 661$ million and operation delay savings of $\$ 908$ million, total benefits were estimated to be $\$ 1,569$ million.

Turning to the cost side, investment costs were assumed to occur so that 10 percent were incurred in 1998, 35 percent in both 1999 and 2000, and 20 percent in 2001 . Annual recurring costs were assumed to be 3 percent of the initial capital cost per year. Table 2 shows the calculated costs. In present value terms, investment costs were estimated to be $\$ 537$ million and recurring costs were estimated to be $\$ 142$ million. These costs are offset to some extent by the disposal value of $\$ 76$ million. ${ }^{29}$ Thus, total costs were estimated to be $\$ 603$ million.

Given the estimated benefits of $\$ 1,569$ million and costs of $\$ 603$ million, the NPV of alternative $\mathrm{W}-1 \mathrm{~W}$ was $\$ 966$ million. Thus, alternative $\mathrm{W}-1 \mathrm{~W}$ was viewed as economically viable. The $\mathrm{B} / \mathrm{C}$ was 2.6.

Step 7: Evaluate the Variability of Benefit-Cost Estimates. Underlying every BCA are numerous assumptions, estimates, and forecasts, which, if inaccurate, may introduce error in the NPV results. A thorough BCA will include a sensitivity analysis, which is a standard tool that varies key assumptions, estimates, and forecasts and provides alternative results for examination.

The evaluation of alternative $\mathrm{W}-1 \mathrm{~W}$ examined three areas of risk: (i) investment cost overruns of 10,25 , and 50 percent; (ii) slippage in the construction schedule by 1,2 , and 5 years; and (iii) three cases in which traffic deviates from forecasted levels after 2005-traffic is held constant at 2005 levels, traffic is at 90 percent of the forecast, and traffic is at 110 percent of forecast.

The NPV and B/C results are shown in Table 3. For each case in which only one variable is altered, the NPV remains positive. A slippage in the construction schedule by five years causes the lowest NPV

\footnotetext{
${ }^{29}$ The disposal value was determined by depreciating the initial capital investment at 3 percent per year until 2021 and then discounting that result to its present value.
} 


\section{Table 1}

\section{Benefit Estimate for $W-1 W^{*}$ (1997 dollars in} millions)

\begin{tabular}{lc} 
Benefit & Present value \\
\hline Passenger delay savings & $\$ 661$ \\
Operational delay savings & $\$ 908$ \\
Total delay savings & $\$ 1,569$ \\
NOTE: *See FAA (1997, Table 4). & \\
\hline
\end{tabular}

\section{Table 2}

\section{Cost Estimate for W-1W* (1997 dollars in} millions)

\begin{tabular}{lc} 
Cost & Present val \\
\hline Investment & $\$ 537$ \\
Recurring & $\$ 142$ \\
Disposal value & $(\$ 76)$ \\
Total cost less disposal value & $\$ 603$
\end{tabular}

NOTE: *See FAA (1997, Table 3).

\section{Table 3}

\section{Sensitivity Analysis for $\mathbf{W}-1 W^{*}$}

\begin{tabular}{lcc} 
Scenario & NPV (1997 dollars in millions) & B/C \\
\hline W-1W as planned & $\$ 966$ & 2.6 \\
Investment cost overrun & & 2.4 \\
$10 \%$ & $\$ 912$ & 2.1 \\
$25 \%$ & $\$ 832$ & 1.8 \\
$50 \%$ & $\$ 698$ & 2.3 \\
Slippage in construction schedule & & 2.1 \\
$\quad$ year & $\$ 795$ & 1.4 \\
2 years & $\$ 639$ & \\
5 years & $\$ 248$ & 1.9 \\
Traffic relative to forecast after 2005 & & 2.2 \\
Constant & $\$ 551$ & 2.7 \\
$90 \%$ of forecast & $\$ 782$ & \\
110\% of forecast & $\$ 1,095$ & 2.1 \\
Two-variable analysis & & 1.7 \\
10\% Overrun and 1-year slippage & $\$ 741$ & 1.0 \\
$25 \%$ overrun and 2-year slippage & $\$ 505$ &
\end{tabular}

of $\$ 248$ million and the lowest B/C of 1.4 . Not surprisingly, the NPV rises to $\$ 1095$ million and the $\mathrm{B} / \mathrm{C}$ rises to 2.7 when traffic exceeds its forecasted levels by 10 percent. Only when the overrun in investment costs is 50 percent and the slippage in the construction schedule is 5 years does the NPV become negative.
Step 8: Recommend a Best Course of Action. The final step of a BCA is to recommend a specific alternative. The FAA recommends that the alternative with the largest, positive NPV be given primary consideration. However, the project sponsor may select another alternative if it provides important hard-to-quantify benefits or is substantially less 
risky than the alternative with the largest NPV. For the BCA of the Lambert expansion performed by the FAA, alternative $\mathrm{W}-1 \mathrm{~W}$ is the preferred alternative. Its NPV is positive and, because it was the only alternative evaluated, there is no option that yields a larger NPV. In addition, the sensitivity analysis suggests that the net effects of $\mathrm{W}-1 \mathrm{~W}$ are likely to be positive under a wide range of scenarios.

\section{AIRPORT EXPANSION IMPACTS THAT GENERATE CONTROVERSY}

Airport expansion projects have impacts far beyond those identified in economic impact studies. Numerous social and environmental impacts that generate much displeasure and contentiousness are the norm. ${ }^{30}$ Lawsuits are filed in opposition to virtually every expansion of a major airport. Opponents generally challenge the right of airport officials to override local zoning rules or increase noise or air pollution. Almost without exception, the legal challenges are unsuccessful. Thus, the projects, albeit delayed, do proceed.

Prior to FAA approval of an expansion project, actions to mitigate adverse effects of expansions are reviewed. Below we take a closer look at two common impacts - one that can be characterized as a social impact and one as an environmental impact.

\section{Displacement and Compensation of People and Businesses}

According to the FAA (1998), the Lambert expansion would necessitate the relocation of 5,680 people, including 2,324 households. Over 1900 residential parcels of property were to be acquired. In addition, the relocation of 75 businesses would be required. The city of Bridgeton was to bear the brunt of the relocation. ${ }^{31}$ To mitigate the substantial disruptive effects, various services designed to educate, inform, and respond to those affected were and are being provided. Nonetheless, controversy abounds.

\footnotetext{
30 A lengthy, but not exhaustive, list of the social and environmental impacts includes the disruption/destruction of communities/ neighborhoods, historic areas, biotic communities, floodplains, farmland, and parks as well as adverse effects on noise levels, air quality, and water quality.

31 Higgins and Chase (2002) state that the cities of Bridgeton and St. Charles brought lawsuits in state court challenging Lambert's right to override local zoning laws and in federal court arguing that the FAA failed to consider more cost-effective ways to improve the airport. The lawsuits failed, and ground on the new runway was broken in July 2001
}

Not surprisingly, many of the homeowners forced to sell their property and relocate were less than pleased with the airport expansion. Litigation between them and the City of St. Louis over condemnation of their homes has been extensive. As reported by McClellan (2001), the litigation has occurred despite the fact that the city has the authority to seize homes and has made "an effort to negotiate with each of the homeowners." Despite attempts to use independent citizens to determine a "fair and reasonable price," some think the city's offers were unfair. Often, residents accept them anyway since they do not want to have to continue fighting, and they want to escape "neighborhoods where nobody dares put money into their homes."

Market forces underlie these compensation prices. Although some might consider the buyout price to be too low, because the homes are already located near the airport and, thus, affected by associated noise, it is likely that the value of these homes and those in surrounding communities already reflects the proximity to the airport. These circumstances might make them less desirable in general in the local real estate market, which we discuss further.

\section{Environmental Issues: Noise}

The expansion of an airport likely leads to additional noise in the area surrounding an airport. Some of the affected area is likely to be acquired by the airport as part of the expansion. To the extent that remaining residential areas must endure increased noise, one can argue that these residents and homeowners should be compensated. Not surprisingly, there is often opposition from local community groups when an airport in an urban area plans to expand. Healy (2002) notes one example of this resistance in the Boston area, which has led to the stipulation that the new runway be used only on "days when northwest winds blow at 11.5 miles per hour or more."

Housing prices are likely affected by airport noise. ${ }^{32}$ Because noise becomes capitalized into property values, it is an example of a pecuniary

\footnotetext{
32 For example, Espey and Lopez (2000) find for the Reno-Sparks, Nevada, area a $\$ 2400$ difference between the prices of homes subject to at least 65 decibels of noise and other equivalent homes. Tompkins et al. (1998) find mixed evidence of capitalization of noise for an airport in Manchester, England. They also found, however, that the benefits of easy access to the airport outweighed other costs associated with proximity, such as noise.
} 
externality. ${ }^{33}$ Consequently, an airport expansion leading to additional noise should be countered with a one-time compensation of property owners to account for this capitalization, or property owners should be helped to take defensive action against the noise. Those who choose to live near airports should not be compensated further, since they receive relatively inexpensive housing and they choose to live there. Local government in Chicago provides an example of city assistance to homeowners: In 1996, mayor Richard M. Daley began a program that has led to the soundproofing of nearly 4,000 homes and 75 schools in communities surrounding O'Hare Airport. In the case of the Lambert expansion, homeowners in a designated area likely to be adversely affected by increased noise were offered three options: sales assistance, sound insulation, or a cash payment. In exchange the airport received the right, known as an avigation easement, to generate increased noise. 34

\section{OTHER POSSIBLE SOLUTIONS TO CONGESTION}

Airport expansions increase the capacity of the air transportation system by increasing the amount of capital. As discussed previously, an alternative solution might entail using the existing capital more efficiently. In this section we examine one such solution, congestion-based pricing of landing fees. ${ }^{35}$

Airport congestion is an example of a true (or technological) externality because the resulting delays imposed from too many aircraft operators choosing to land at peak hours causes disutility to others who are waiting to use the runways. Some researchers, most notably Morrison and Winston (1989), have argued in favor of congestion-based pricing of landing fees to solve the airport congestion

\footnotetext{
33 Some argue that because airport noise is an externality, government intervention is necessary. Baumol and Oates (1988, p. 17) provide a required condition for a (technological) externality to be present: "An externality is present whenever some individual's (say A's) utility or production relationships include real (that is, nonmonetary) variables, whose values are chosen by others (persons, corporations, governments) without particular attention to the effects on A's welfare." However, they note that a pecuniary externality (as opposed to a technological externality) occurs when one person's actions affect the financial circumstances of another. A pecuniary externality occurs when one person's actions affect only the prices that another party faces, and thus it is not an externality that necessitates governmental intervention.

34 See FAA (1998) for details.

35 The inefficiencies that result in frequent delays at airports have convinced some that airports should be privatized. See Morrison and Winston (2000) for a discussion of airport privatization.
}

problem. They claim that this type of pricing system may make airport use more efficient. At most airports, landing fees are structured according to aircraft size or weight, and the runway capacity is allocated to aircraft on a "first come, first served" basis (Bailey, 2002). Under the current system, there is a market failure due to the fact that aircraft owners fail to internalize (i.e., fully bear) the costs to society that arise when they choose to land at an already busy airport. These costs come in the form of travel time delay due to longer taxi lines, circling of aircraft before being cleared for landing, etc.

With congestion-based pricing, the owners of aircraft would pay landing fees based on the marginal damage in terms of runway delay that is caused by their aircraft rather than pay fees based on aircraft size or weight. These fees might vary at a particular airport depending on the time of day. This way, when deciding when and where to land, an owner of an aircraft would be forced to consider the marginal social costs of landing at a particular airport at a particular time, instead of merely looking at the marginal private costs. Thus, congestionbased landing fees can correct for the externality that causes congestion at certain airports at certain times of the day. But it also has implications for equity, since small planes would pay as much as large ones at any given time of day. The FAA is considering imposing congestion-based landing fees at some airports, including New York's La Guardia airport and Boston's Logan airport. 36

The arguments for congestion pricing made by Morrison and Winston are similar to studies from the road-pricing literature discussed by Small (1992), where there are many users of the public infrastructure. But in the case of most airports, many of the airport users (i.e., airlines) have market power, which differs from the road-pricing case. Brueckner (2002a) shows that when an airport is dominated by a single monopolist airline, the congestion effects are completely internalized by the airline, thus providing no role for congestion pricing. In competitive situations, even when the number of competitors is two, the airlines do not internalize the congestion that they impose on each other. Thus, there would be a role for congestion pricing, where the toll varies inversely with the carrier's flight share.

Another possible solution to airport congestion is airline route restructuring. As reported by McCartney (2002), American Airlines recently

\footnotetext{
${ }^{36}$ See Brueckner (2002b) and Boston Globe (2002).
} 
announced that they would begin to move away from the traditional "hub and spoke" route structure at some of their hubs and move toward a "rolling hub" structure where passengers wait for planes to arrive at hubs instead of planes waiting for passengers to arrive. Southwest Airlines has been successful at implementing such a route structure, and if enough airlines were to adopt such a structure there could be noticeable amelioration of congestion.

\section{CONCLUSIONS}

Air transportation services play an important role in every metropolitan area. Congestion is a problem at many of these airports. Because of the network features of the air transportation system, congestion at one airport can have adverse effects on the operations at other airports. The large cost associated with congestion provides the incentive for mitigating congestion. But, finding satisfactory solutions is complicated by the interconnectedness of the air transportation system. In this paper, we reviewed the economic analyses and issues associated with one common solution, expanding the capacity of airports. While an expansion may reduce congestion, we show that congestion may persist.

Expanding an airport is a complex undertaking that requires a large capital expenditure. A fundamental question is whether the benefits of the project exceed its costs. Ideally, the proposed expansion maximizes the net present value of the difference between the benefits and the costs. By examining the steps in a benefit-cost analysis for LambertSt. Louis International Airport, we illustrate the economic analysis that underlies a typical expansion project.

The benefits of an expansion project to users of air transportation services extend throughout the local economy and likely beyond, whereas some significant social and environmental impacts are concentrated near the airport. Not surprisingly, the typical expansion project is controversial, with lawsuits being quite common. We attempt to illustrate these social and environmental effects and examine ways to mitigate their adverse effects. Airport expansions frequently disrupt neighborhoods and nearby communities, an example of which is the destruction of homes in Bridgeton that was judged to be a necessary part of the Lambert expansion. Homeowners received compensation for their property, but entire neighborhoods were destroyed. Another disruption is the additional noise imposed on surrounding communities due to larger airports.
The new runway project in Boston and the associated noise led to agreements on limitations of its future use.

Finally, we examined an alternative to expansion-congestion pricing - that attempts to use the existing airport capital more efficiently. We demonstrate that a tax on airport users would improve airport efficiency. This is consistent to some extent with the notion of congestion pricing, which posits that users should be charged separate landing fees, based on the marginal damage in terms of travel delays that given users impose on others.

\section{REFERENCES}

Air Transport Association. Airline Handbook, 2001.

< http://www.airlines.org/public/publications/

display 1 .asp? nid $=961>$.

Aschauer, David A. "Is Public Expenditure Productive?" Journal of Monetary Economics, March 1989, 23(2), pp. 177-200.

"Do States Optimize? Public Capital and Economic Growth." Annals of Regional Science, August 2000a, 34(3), pp. 343-63.

"Public Capital and Economic Growth: Issues of Quantity, Finance, and Efficiency." Economic Development and Cultural Change, January 2000b, 48(2), pp. 391-406.

Bailey, Elizabeth E. "Aviation Policy: Past and Present." Southern Economic Journal, July 2002, 69(1), pp. 12-20.

Barro, Robert J. "Government Spending in a Simple Model of Endogenous Growth." Journal of Political Economy, October 1990, 98(5, Part 2), pp. 103-26.

Baumol, William J. and Oates, Wallace E. The Theory of Environmental Policy. Second Edition. Cambridge: Cambridge University Press, 1988.

Bayles, Fred. "Airport Expansion Plans Come to Screeching Halt." USA Today, 12 November 2001, p. 6B.

Boston Globe. "A Runway If..." Editorial, 25 June 2002, p. A14.

Brueckner, Jan K. "Airport Congestion When Carriers Have Market Power." American Economic Review, December 2002a, 92(5), pp. 1357-75. 
"Internalization of Airport Congestion."

Journal of Air Transport Management, May 2002b, 8(3), pp. 141-47.

"Airline Traffic and Urban Economic

Development.” Urban Studies, 2003 (forthcoming).

Case, Anne C.; Rosen, Harvey S. and Hines, James R. Jr. "Budget Spillovers and Fiscal Policy Interdependence: Evidence from the States." Journal of Public Economics, October 1993, 52(3), pp. 285-307.

Cohen, Jeffrey P. "Some Issues in Benefit Cost Analysis for Airport Development.” Transportation Research Record, July 1997, No. 1567, pp. 1-7.

"Reciprocal State and Local Airport Spending Spillovers and Symmetric Responses to Cuts and Increases in Federal Airport Grants." Public Finance Review, January 2002, 30(1), pp. 41-55.

and Morrison Paul, Catherine J. "Airport Infrastructure Spillovers in a Hub and Spoke System." Working Paper 01-011, University of California-Davis, Department of Agricultural and Resource Economics, December 2001.

Cooper, Ronald. "Airports and Economic Development: An Overview." Transportation Research Record, 1990, No. 1274, pp. 125-33.

Coughlin, Cletus C.; Cohen, Jeffrey P. and Khan, Sarosh. "Aviation Security and Terrorism: A Review of the Economic Issues." Federal Reserve Bank of St. Louis Review, September/October 2002, 84(5), pp. 9-24.

and Mandelbaum, Thomas B. "A Consumer's Guide to Regional Economic Multipliers." Federal Reserve Bank of St. Louis Review, January/February 1991, 73(1), pp. 19-32.

Easterly, William and Rebelo, Sergio. "Fiscal Policy and Economic Growth: An Empirical Investigation.” Journal of Monetary Economics, December 1993, 32(3), pp. 417-58.

Espey, Molly and Lopez, Hilary. "The Impact of Airport Noise and Proximity on Residential Property Values." Growth and Change, Summer 2000, 31(3), pp. 408-19.

Federal Aviation Administration. Benefit-Cost Analysis for Lambert-St. Louis International Airport Capacity Enhancement Project, July 1997.
Record of Decision on Lambert-St. Louis International Airport, September 1998.

Office of Aviation Policy and Plans. FAA Airport Benefit-Cost Analysis Guidance, December 1999.

Gilbert, Virginia Baldwin. "Lambert Field Tunnel Will Be First of Its Kind." St. Louis Post-Dispatch, 17 November 2002, pp. F1,8.

Gillen, David and Lall, Ashish. "International Transmission of Shocks in the Airline Industry." Journal of Air Transport Management, January 2003, 9(1), pp. 37-49.

Golaszewski, Richard. "Network Industries in Collision: Aviation Infrastructure Capacity, Financing and the Exposure to Traffic Declines." Journal of Air Transport Management, January 2003, 9(1), pp. 57-65.

Gramlich, Edward M. "Intergovernmental Grants: A Review of the Empirical Literature," in Wallace E. Oates, ed., The Political Economy of Fiscal Federalism. Lexington, MA: Heath-Lexington, 1977, pp. 219-39.

Hakfoort, Jacco; Poot, Tom and Rietveld, Piet. "The Regional Economic Impact of an Airport: The Case of Amsterdam Schiphol Airport." Regional Studies, October 2001, 35(7), pp. 595-604.

Healy, Jack. "FAA Seen Giving Boost to New Logan Runway: Foes Greet Plan with Skepticism." Boston Globe, 22 June 2002, pp. A1,5.

Higgins, Michael and Chase, John. "Suits Over Airport Projects Rarely Win but Often Delay." Chicago Tribune, 4 June 2002, news section p. 1.

Lahr, Michael L. and Dietzenbacher, Erik eds. Input-Output Analysis: Frontiers and Extensions. New York: Palgrave, 2001.

Lighart, Jenny E. "Public Capital and Output Growth in Portugal: An Empirical Analysis.” Working Paper No. 00/11, International Monetary Fund, January 2000.

McCartney, Scott. "Clipped Wings: American Airlines to Retrench in Bid to Beat Discount Carriers.” Wall Street Journal, 13 August 2002, p. A1.

McClellan, Bill. "Bridgeton Die-Hards Live To Fight Over Airport Expansion.” St. Louis Post-Dispatch, 2 September 2001, p. C1. 
McRainey, Megan. “\# 1: Hartsfield Soars with Atlanta.” Atlanta Business Chronicle, 27 May 2002. < http:/l atlanta.bizjournals.com/atlanta/stories/2002/05/27/ focus1.html > .

Miller, Ronald E. "Regional and Interregional Input-Output Analysis," in Walter Isard et al., eds., Methods of Interregional and Regional Analysis. Aldershot, England: Ashgate, 1998, pp. 41-134.

Montavlo, Jose G. "A Methodological Proposal to Analyze the Economic Impacts of Airports." International Journal of Transport Economics, June 1998, 25(2), pp. 181-203.

Morrison, Steven A. and Winston, Clifford. "Enhancing the Performance of the Deregulated Air Transportation System." Brookings Papers on Economic Activity: Microeconomics, Special Issue 1989, pp. 61-112.

and "The Remaining Role of Government Policy in the Deregulated Airline Industry," in Sam Peltzman and Clifford Winston, eds., Deregulation of Network Industries: What's Next? AEI-Brookings Joint Center for Regulatory Studies, 2000, pp. 1-40.

Mumphrey Group. Economic Impact Study, prepared for Lambert-St. Louis International Airport, City of St. Louis Airport Authority, January 1996.

Munnell, Alicia H. "How Does Public Infrastructure Affect Regional Economic Performance?” New England Economic Review, September/October 1990, pp. 11-32.

Niemeier, Hans-Martin. "On the Use and Abuse of Impact Analysis for Airports: A Critical View from the Perspective of Regional Policy," in Wilhem Pfähler, ed., Regional Input-Output Analysis: Conceptual Issues, Airport Case Studies, and Extensions. Baden-Baden, Germany: Nomos, 2001, pp. 201-20.

Oates, Wallace. Fiscal Federalism. 5th Edition. New York: Harcourt, Brace, Jovanovich, 1972.

O'Sullivan, Arthur. Urban Economics. New York: McGraw-Hill, 2003.

Pfähler, Wilhelm, ed., "Input-Output Analysis: A User's Guide and Call for Standardization." Regional Input-Output Analysis: Conceptual Issues, Airport Case Studies, and Extensions. Baden-Baden, Germany: Nomos, 2001, pp. 11-45.

Salant, Jonathan D. "Airports Across the Country Tardy." Associated Press, 22 July 2001.

Sanders, Heywood T. "Convention Myths and Markets: A Critical Review of Convention Center Feasibility Studies." Economic Development Quarterly, August 2002, 16(3), pp. 195-210.

Small, Kenneth A. Urban Transportation Economics. Chur, Switzerland: Harwood Academic Publishers, 1992.

Tomkins, J.; Topham, N.; Twomey, J. and Ward, R. "Noise versus Access: The Impact of an Airport in an Urban Property Market." Urban Studies, February 1998, 35(2), pp. 243-58.

Truitt, Lawrence J. and Esler, Michael. "Airport Privatization: Full Divestiture and Its Alternatives.” Policy Studies Journal, 1996, 24(1), pp. 100-10. 
